\title{
Tendência histórica de preços pagos ao produtor de hortifrutigranjeiros do Rio Grande do Sul, Brasil
}

\author{
Historical Tendency of prices paid to the horticultural farmers in Rio Grande do Sul, Brazil
}

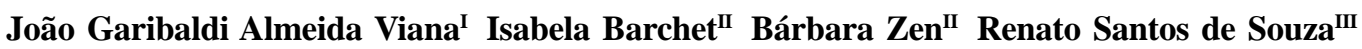

RESUMO

O presente trabalho tem como objetivo analisar a evolução histórica dos preços pagos ao produtor de hortifrutigranjeiros do Rio Grande do Sul no período de 1973 a 2006, dando especial atenção ao período anterior e posterior à estabilização monetária alcançada com o Plano Real de 1994. As séries históricas de preços nominais mensais dos produtos hortifrutigranjeiros analisados (aipim, batata, cebola, tomate, laranja, bergamota, maçã, pêssego e uva) foram disponibilizadas pela EMATER-RS. O trabalho permitiu concluir que todos os produtos analisados apresentaram desvalorização significativa em seus preços de 1973 a 2006. Constatou-se que a década de 1980 foi o período de maior desvalorização para a horticultura, e o período pós-Plano Real foi o de maior desvalorização para a fruticultura.

Palavras-chave: preços agrícolas, hortifrutigranjeiros, séries temporais.

\section{ABSTRACT}

The aim of this study is to analyze the historical evolution of prices paid to the horticultural farmers in Rio Grande do Sul, between 1973 and 2006, paying especial attention to the period before and after the monetary stabilization achieved through the Plano Real, in 1994. The historical series of nominal monthly prices of the analyzed horticultural products (cassava, potatoes, onions, tomatoes, oranges, satsumas, apples, peaches and grapes) were obtained from EMATER-RS. Through this study it was possible to conclude that all of the products analyzed had a significant decline in their prices from 1973 to 2006. It was verified that the eighties represent the period with the highest price drops for horticulture, and the period after the implementation of the Plano Real had the strongest price reductions for fruits.
Key words: farming prices, olericulture, fruticulture, temporal series.

\section{INTRODUÇÃO}

A grande diversidade de climas e solos existente no Brasil constitui excelente ambiente para a expansão da produção de frutas e hortaliças. Essa vantagem, porém, é condição necessária, mas não suficiente para o sucesso de empreendimentos no setor. As especificidades do sistema agroindustrial das frutas, em especial o fato de direcionar-se para um público de maior poder aquisitivo, obriga as cadeias produtivas a levarem em conta fatores como regularidade no fornecimento, capacidade de adaptação às novas exigências dos consumidores e atendimento a segmentos diferenciados de consumo.

Apesar de grande produtor, o país apresenta limitações com relação a esses aspectos. A visão de cadeia produtiva é ainda algo novo no país, e as relações de parceria são frágeis. Assim, a competitividade da fruticultura brasileira está dependente do avanço em torno dessa nova visão e da adoção de procedimentos compatíveis com a ideia de cadeia produtiva.

Segundo ALMEIDA (2008), o mercado interno é, e continuará sendo, o principal destino da produção nacional de frutas, o que é natural se for

\footnotetext{
ICurso de Pós-graduação em Agronegócios, Universidade Federal do Rio Grande do Sul (UFRGS), Porto Alegre, RS, Brasil.

IICurso de Ciências Econômicas, Universidade Federal de Santa Maria (UFSM), Santa Maria, RS, Brasil.

IIIDepartamento de Educação Agrícola e Extensão Rural, UFSM, Prédio 44, Faixa de Camobi, km 09, 97105-900, Santa Maria, RS, Brasil. E-mail: rssouza@smail.ufsm.br. Autor para correspondência.
} 
considerada a demanda da população brasileira, mesmo sendo pequeno o consumo per capita. Ao mercado externo, são destinados menos de $3 \%$ da produção de frutas frescas, e as exportações de frutas e derivados ainda são muito concentradas quanto ao tipo de fruta (uva, melão, manga, maçã, banana, limão e mamão) e quanto ao mercado de destino (especialmente União Europeia e Estados Unidos, que juntos respondem por mais de $90 \%$ das exportações brasileiras). Ainda segundo o autor, consegue exportar aquele produtor que tem tecnologia adequada de produção, custos competitivos, qualidade de fruto, variedades adequadas, capital, logística e acesso aos distribuidores, o que, infelizmente, apenas uma pequena parcela dos produtores brasileiros de frutas consegue atender.

Dentre as atividades agropecuárias, a fruticultura e a horticultura estão entre as maiores demandadoras de mão-de-obra, sobretudo no setor primário (VILELA \& HENZ, 2000; ALMEIDA, 2008). Num país com carência de emprego e de melhores condições de vida no meio rural, esse seu potencial empregador pode contribuir para minimizar problemas como o êxodo rural, o desemprego permanente ou sazonal e a baixa retenção de renda pelo segmento produtivo.

Bastante dinâmico, o mercado de hortaliças é fortemente influenciado pela preferência dos consumidores, que também tem redirecionado a produção. As hortaliças, vegetais tidos como mais lucrativos que outras culturas, como os grãos, por exemplo, têm uma realidade bem mais complexa (VILELA \& HENZ, 2000), e o sucesso dos negócios com esse grupo de alimentos depende de muitos fatores. Em primeiro lugar, deve-se considerar que as hortaliças são culturas temporárias e, assim como as outras, necessitam de um investimento inicial. No entanto, apesar das variações cíclicas e sazonais das hortaliças, os negócios com essas culturas vêm sendo bastante atrativos. Uma das principais características do mercado atual de hortaliças é a oferta de produtos com variações em relação ao que já é conhecido, seja em tamanho, cor ou sabor, e buscando se estruturar em diferentes segmentos, não dependendo apenas de produtos in natura.

Em face dessas questões do mercado de hortifrutigranjeiros, torna-se relevante estudar como a evolução da atividade e das políticas para o setor hortifrutigranjeiro refletiu-se nos preços do produto, de forma que se possa melhor avaliar a distribuição dos custos e benefícios de tais mudanças para os diferentes agentes da cadeia produtiva e consumidores finais.
Assim, este trabalho teve por objetivo analisar evolução histórica dos preços pagos ao produtor de hortifrutigranjeiros do Rio Grande do Sul no período de 1973 a 2006, dando especial atenção ao período anterior e posterior à estabilização monetária alcançada com o Plano Real de 1994. Mais especificamente, pretendeu-se verificar a existência ou não de tendência histórica e o sentido desta. Trata-se, portanto, da continuidade dos trabalhos já desenvolvidos para os preços dos produtos pecuários e dos produtos da agricultura de grãos, cujos resultados encontram-se publicados em SOUZA et al. (2006) e SOUZA \& VIANA (2007).

\section{MATERIAL E MÉTODOS}

O estudo foi realizado com base no histórico de preços médios mensais pagos ao produtor de hortifrutigranjeiros, coletados pela EMATER-RS. As informações abrangem dois períodos distintos, em função dos dados disponibilizados pela EMATER: de janeiro de 1973 a dezembro de 2006, para os produtos cebola, pêssego, tomate, batata e laranja, e de janeiro de 1986 a dezembro de 2006, para os produtos uva de mesa, aipim, bergamota e maçã. Além disso, também em função da disponibilidade de dados, os preços nominais apresentam valores mensais para os produtos cebola, tomate, aipim, batata e laranja, enquanto produtos com oferta estacional apresentam valores apenas nos período de safra, como: pêssego (outubro a março), uva de mesa (dezembro a março), bergamota (junho a outubro) e maçã (fevereiro a julho). Para esses produtores, pela carência de oferta, não há formação de preços ao produtor fora dos períodos de safra.

A metodologia utilizada no presente trabalho é idêntica à utilizada em SOUZA et al. (2006) e SOUZA \& VIANA (2007) e consistiu, inicialmente, em fazer as correções monetárias nos preços nominais históricos relativas aos diferentes planos econômicos (Plano Cruzado, Plano Verão, Plano Collor e Plano Real) e deflacionar os preços corrigidos de cada mês de forma a atualizá-los para valores reais equivalentes a dezembro de 2006. Para o deflacionamento dos preços nominais, foi utilizado o Índice Geral de Preços (IGP-DI), calculado pela Fundação Getulio Vargas. Para cada um dos produtos analisados, foi também calculado um índice de evolução dos preços reais médios anuais, com base 100, em janeiro 1973 e janeiro de 1986, para hortifrutigranjeiros com produção contínua e produtos de safra, respectivamente, de forma a permitir comparações entre os movimentos de preços dos diferentes produtos. 
Por fim, buscou-se verificar a existência de tendência de preços para os produtos estudados. Várias são as formas de se avaliar a existência ou não de tendência em uma série temporal de dados, entre elas, estão o uso da taxa geométrica de crescimento (FINAMORE \& GOMES, 1999) e do coeficiente angular da reta de regressão dos dados (KAZMIER, 1982). Em razão da simplicidade de interpretação e da eficiência do segundo método em relação ao objetivo proposto neste artigo, optou-se por ele.

A fim de verificar se houve, nos períodos em estudo, tendência declinante ou de alta nos preços foram ajustadas retas de regressão sobre os preços reais para os períodos de 1973-1994, 1995-2006 e 1973-2006 (cebola, pêssego, tomate, batata elaranja)e 19861994, 1995-2006 e 1986-2006 (uva demesa, aipim, bergamota e maçã), sendo utilizado o método dos mínimos quadrados, conforme JOHNSTON (1977). Tal regressão, com a qual se estimou a equação 1 , teve como variável dependente o preço real médio anual desestacionalizado (para os produtos de série contínua), ou o preço real médio do período disponível (para os produtos de safra). Como variável independente, foi utilizado o período de tempo (em anos).

$\mathrm{PT}=\mathrm{a}+\mathrm{b} . \mathrm{T}$ (1), em que: $\mathrm{PT}=$ preço de tendência; $a=$ coeficiente linear da reta de tendência; $b=$ coeficiente angular da reta de tendência; e $\mathrm{T}=$ período de tempo $(1,2,3,4,5 \ldots \mathrm{n})$.

Como a regressão foi feita com base no preço anual médio desestacionalizado para os produtos com valores mensais contínuos, foi necessário calcular, para cada mês, o "Índice de Estacionalidade” médio, o que se fez utilizando o método das médias móveis de 13 meses preconizado por KAZMIER (1982). Em seguida, os preços mensais foram desestacionalizados para retirar destes as variações estacionais e de curto prazo, deixando, na série temporal, apenas as variações cíclicas e de tendência, possibilitando, com isso, que se fizesse a regressão com base nos preços médios anuais, o que é mais conveniente e dá maior consistência à análise de tendência.

A existência ou não de tendência declinante ou ascendente nos preços reais dos diferentes produtos no período analisado foi verificada por meio do teste de hipóteses t-student, com o qual se avaliou, em um nível de 95\% de significância, se o coeficiente angular " $b$ " da reta de regressão ajustada aos dados era significativamente diferente de zero. Mais detalhes sobre a metodologia do trabalho podem ser consultados em SOUZA et al. (2006) e SOUZA \& VIANA (2007).

\section{RESULTADOS E DISCUSSÃO}

Os produtos hortifrutigranjeiros pesquisados (cebola, tomate, batata, laranja, pêssego, uva de mesa, bergamota, maçã e aipim) apresentaram queda significativa de preços no período entre 1973 e 2006, como pode ser observado nas tabelas 1 e 2, para os produtos com série completa (1973 a 2006), e nas tabelas 3 e 4, para produtos com série a partir 1986. Entre os produtos com maior desvalorização nos períodos em análise, encontra-se a cebola e o pêssego com decréscimo de preço a partir de 1973 de 84,1 e 64,6\%, respectivamente. A bergamota apresentou desvalorização de 63,2\% de 1986 a 2006. Os produtos que apresentaram menor desvalorização foram a maçã, com 31,4\%, e a laranja, com 38,8\%.

A desvalorização dos preços dos produtos em análise nas últimas décadas tem correlação direta com o aumento da produtividade e da oferta dos produtos hortifrutigranjeiros. A adoção de novas tecnologias de produção, possibilitando maior produtividade por área e maior interesse empresarial pela produção e distribuição de hortifrutigranjeiros, são elementos importantes para entender a queda significativa de preços. O aumento na oferta de produtos e o incremento de renda obtidos a partir do Plano Real estimularam o maior consumo por partes dos consumidores. Novas formas de processamento, principalmente das frutas, cresceram nos últimos anos. CARDOSO et al. (2000) destacam a tendência de aumento $(37,2 \%)$ do consumo de bebidas não alcoólicas, que de certa forma usam na sua preparação uma quantidade relevante de frutas de clima tropical.

O período de maior desvalorização dos preços da maioria dos produtos frutícolas foi o período pós-Plano Real, ao contrário do que foi observado com os produtos de origem pecuária e da agricultura de grãos, que apresentaram maior desvalorização de preços durante a década de 1980, conforme SOUZA, et al. (2006) e SOUZA \& VIANA (2007).

No caso da laranja, evidencia-se um comportamento de oscilações de preços durante a década de 1970 e 1980 e, posteriormente, uma queda acentuada dos preços pagos ao produtor a partir de 1994, com desvalorização significativa nos anos subsequentes. A desvalorização dos preços da laranja foi acompanhada pelo crescimento acentuado da 
Tabela 1 - Preços reais médios (R\$) pagos ao produtor, atualizados para dezembro de 2006, dos principais produtos hortifrutigranjeiros do Rio Grande do Sul.

\begin{tabular}{|c|c|c|c|c|c|}
\hline \multicolumn{5}{|c|}{ Produtos de série contínua } & \multirow{2}{*}{$\begin{array}{l}\text { Produtos de Safra } \\
\left.\text { Pêssego ( } \mathrm{R} \$ \mathrm{~kg}^{-1}\right)\end{array}$} \\
\hline Produto & Cebola $\left(\mathrm{R} \$ \mathrm{~kg}^{-1}\right)$ & Tomate $\left(\mathrm{R} \$ \mathrm{~kg}^{-1}\right)$ & Batata $\left(\mathrm{R} \$ \mathrm{~kg}^{-1}\right)$ & Laranja $\left(\mathrm{R} \$ \mathrm{~kg}^{-1}\right)$ & \\
\hline \multicolumn{6}{|l|}{ Ano } \\
\hline 1973 & 4,24 & 2,70 & 2,00 & 0,56 & 3,49 \\
\hline 1974 & 2,01 & 2,90 & 1,52 & 0,57 & 3,05 \\
\hline 1975 & 2,49 & 2,84 & 1,34 & 0,56 & 2,93 \\
\hline 1976 & 2,64 & 3,19 & 1,94 & 0,70 & 3,14 \\
\hline 1977 & 2,14 & 2,86 & 1,48 & 0,63 & 2,58 \\
\hline 1978 & 5,54 & 2,98 & 2,03 & 0,80 & 2,47 \\
\hline 1979 & 2,51 & 2,65 & 1,33 & 0,82 & 2,39 \\
\hline 1980 & 3,64 & 3,18 & 2,47 & 0,66 & 2,43 \\
\hline 1981 & 1,23 & 2,61 & 2,05 & 0,65 & 1,80 \\
\hline 1982 & 2,87 & 2,42 & 1,39 & 0,55 & 2,98 \\
\hline 1983 & 2,45 & 2,82 & 2,89 & 0,59 & 2,25 \\
\hline 1984 & 2,26 & 2,35 & 1,51 & 0,82 & 2,39 \\
\hline 1985 & 2,65 & 2,43 & 1,35 & 0,63 & 2,69 \\
\hline 1986 & 2,33 & 4,24 & 2,60 & 0,79 & 3,32 \\
\hline 1987 & 1,02 & 2,67 & 1,28 & 0,75 & 2,15 \\
\hline 1988 & 1,72 & 1,83 & 0,67 & 0,48 & 2,19 \\
\hline 1989 & 0,85 & 2,66 & 1,33 & 0,62 & 2,23 \\
\hline 1990 & 1,55 & 2,20 & 0,83 & 0,50 & 1,60 \\
\hline 1991 & 0,97 & 1,87 & 0,95 & 0,66 & 1,42 \\
\hline 1992 & 0,45 & 1,41 & 0,71 & 0,65 & 1,41 \\
\hline 1993 & 1,11 & 1,66 & 0,63 & 0,36 & 1,35 \\
\hline 1994 & 0,77 & 2,58 & 0,93 & 0,82 & 2,67 \\
\hline 1995 & 0,97 & 1,97 & 0,70 & 0,73 & 3,51 \\
\hline 1996 & 0,32 & 1,83 & 0,54 & 0,44 & 1,45 \\
\hline 1997 & 1,08 & 1,43 & 0,64 & 0,28 & 1,44 \\
\hline 1998 & 0,92 & 1,60 & 0,98 & 0,25 & 1,81 \\
\hline 1999 & 0,61 & 1,33 & 0,54 & 0,39 & 0,96 \\
\hline 2000 & 0,66 & 1,47 & 0,52 & 0,24 & 1,18 \\
\hline 2001 & 0,85 & 1,14 & 0,81 & 0,26 & 0,96 \\
\hline 2002 & 0,80 & 1,21 & 0,66 & 0,30 & 1,07 \\
\hline 2003 & 0,82 & 1,46 & 0,85 & 0,33 & 0,98 \\
\hline 2004 & 0,95 & 1,31 & 0,73 & 0,31 & 1,41 \\
\hline 2005 & 0,67 & 1,29 & 0,85 & 0,29 & 1,57 \\
\hline 2006 & 0,67 & 1,23 & 0,79 & 0,34 & 1,24 \\
\hline
\end{tabular}

Fonte: Cálculos dos autores a partir de dados primários da EMATER-RS.

produção brasileira. De 1980 a 2006, a produção cresceu $127 \%$ segundo dados de ABECITRUS (2008). Uma exceção observada foi o comportamento dos preços pagos ao produtor de batata. A maior desvalorização desse produto foi observada na década de 1980, após grandes oscilações de preços nos anos anteriores. A partir de 1990, os preços da batata se estabilizaram e, após 1995, apresentaram tendência significativa de elevação até 2006. O preço pago ao produtor de batata no ano de 2006 foi $12,8 \%$ superior aos preços praticados no ano de 1995. Essa elevação foi condicionada pelo aumento do consumo interno nas última décadas, aliado ao decréscimo da produção do produto na região Sul, com uma redução de 8,7\% de 1996 a 2004, segundo dados deABBA(2008).

As tabelas 5 e 6 mostram os resultados da regressão elaborada para fins de análise de tendência. Conforme os dados das tabelas, todos os produtos apresentaram acentuada tendência declinante de preços no período 1973-2006 e 1986-2006. Porém, ao analisar o período 1995-2006, posterior à estabilização econômica, observa-se que os produtos batata e aipim apresentaram tendência de elevação significativa de preços pós-Plano Real. Os produtos cebola e maçã não apresentaram tendência de queda nem elevação no 
Tabela 2 - Índices de preços médios anuais pagos ao produtor dos principais produtos hortifrutigranjeiros do Rio Grande do Sul (base 100 em 1986).

\begin{tabular}{|c|c|c|c|c|c|}
\hline \multicolumn{5}{|c|}{ Produtos de série contínua } & \multirow{2}{*}{$\begin{array}{c}\text { Produtos de Safra } \\
\text { Pêssego }\end{array}$} \\
\hline Produto & Cebola & Tomate & Batata & Laranja & \\
\hline \multicolumn{6}{|l|}{ Ano } \\
\hline 1973 & 178,24 & 63,79 & 77,11 & 71,26 & 105,18 \\
\hline 1974 & 86,20 & 68,46 & 58,44 & 72,54 & 91,82 \\
\hline 1975 & 106,72 & 66,91 & 51,74 & 70,72 & 88,31 \\
\hline 1976 & 113,01 & 75,33 & 74,73 & 88,62 & 94,60 \\
\hline 1977 & 91,77 & 67,34 & 56,94 & 79,91 & 77,71 \\
\hline 1978 & 237,24 & 70,38 & 77,98 & 101,76 & 74,49 \\
\hline 1979 & 107,57 & 62,53 & 51,32 & 104,43 & 71,96 \\
\hline 1980 & 155,83 & 75,12 & 95,10 & 83,62 & 73,24 \\
\hline 1981 & 52,59 & 61,52 & 78,80 & 82,25 & 54,17 \\
\hline 1982 & 123,05 & 57,09 & 53,32 & 70,57 & 89,77 \\
\hline 1983 & 104,82 & 66,53 & 111,27 & 75,04 & 67,80 \\
\hline 1984 & 96,93 & 55,44 & 58,19 & 104,72 & 71,97 \\
\hline 1985 & 113,68 & 57,32 & 51,81 & 80,07 & 81,14 \\
\hline 1986 & 100,00 & 100,00 & 100,00 & 100,00 & 100,00 \\
\hline 1987 & 43,50 & 63,06 & 49,19 & 57,41 & 64,71 \\
\hline 1988 & 73,69 & 43,17 & 25,95 & 61,12 & 66,05 \\
\hline 1989 & 36,46 & 62,84 & 51,03 & 78,44 & 67,22 \\
\hline 1990 & 66,39 & 51,83 & 32,12 & 64,03 & 48,08 \\
\hline 1991 & 41,56 & 44,07 & 36,50 & 83,63 & 42,73 \\
\hline 1992 & 19,30 & 33,28 & 27,38 & 82,42 & 42,53 \\
\hline 1993 & 47,58 & 39,20 & 24,32 & 45,42 & 40,56 \\
\hline 1994 & 33,11 & 60,96 & 35,84 & 104,19 & 80,53 \\
\hline 1995 & 41,57 & 46,39 & 26,79 & 92,67 & 105,86 \\
\hline 1996 & 13,93 & 43,10 & 20,67 & 56,18 & 43,60 \\
\hline 1997 & 46,39 & 33,65 & 24,60 & 36,14 & 43,38 \\
\hline 1998 & 39,40 & 37,71 & 37,74 & 31,23 & 54,51 \\
\hline 1999 & 26,20 & 31,33 & 20,66 & 49,27 & 28,89 \\
\hline 2000 & 28,17 & 34,68 & 19,89 & 29,99 & 35,71 \\
\hline 2001 & 36,40 & 26,94 & 31,23 & 33,03 & 28,93 \\
\hline 2002 & 34,33 & 28,56 & 25,48 & 38,61 & 32,36 \\
\hline 2003 & 35,07 & 34,37 & 32,68 & 42,37 & 29,66 \\
\hline 2004 & 40,82 & 31,00 & 28,26 & 39,68 & 42,59 \\
\hline 2005 & 28,90 & 30,52 & 32,71 & 37,27 & 47,22 \\
\hline 2006 & 28,83 & 28,97 & 30,41 & 43,63 & 37,27 \\
\hline
\end{tabular}

Fonte: Cálculos dos autores a partir de dados primários da EMATER-RS.

período pós-Plano Real, o que demonstra um comportamento de estabilidade de preços nos últimos anos. Os demais produtos apresentaram desvalorização significativa no período pós-Plano Real (Tabelas 5 e 6).

\section{CONCLUSÃO}

Por meio deste trabalho, pode-se observar que os preços pagos ao produtor pelos produtos hortifrutigranjeiros selecionados apresentaram desvalorização significativa em ambos os períodos, 1973 a 2006 e 1986 a 2006. Em uma análise generalizada, observou-se que a maioria dos produtos da horticultura apresentou maior desvalorização durante a década de 1980, enquanto os produtos da fruticultura apresentaram maiores desvalorização no período pósPlano Real. O trabalho demonstra ainda que, nesse período, produtos como batata e aipim apresentaram elevação significativa de preço, e a cebola e a maçã não apresentaram tendência de queda nem elevação. Enquanto isso, os demais produtos selecionados apresentaram desvalorização significativa pós 1994. 
Viana et al.

Tabela 3 - Preços reais médios (R\$) pagos ao produtor, atualizados para dezembro de 2006, dos principais produtos hortifrutigranjeiros do Rio Grande do Sul.

\begin{tabular}{|c|c|c|c|c|}
\hline \multicolumn{4}{|c|}{ Produtos de Safra } & \multirow{2}{*}{$\frac{\text { Produtos de série contínua }}{\text { Aipim }\left(\mathrm{R} \$ \mathrm{~kg}^{-1}\right)}$} \\
\hline Produto & Uva de mesa $\left(\mathrm{R} \$ \mathrm{~kg}^{-1}\right)$ & Bergamota $\left(\mathrm{R} \$ \mathrm{~kg}^{-1}\right)$ & Maçã $\left(\mathrm{R} \$\right.$ kg$\left.^{-1}\right)$ & \\
\hline Ano & & & & \\
\hline 1986 & 2,77 & 1,15 & 1,87 & 0,95 \\
\hline 1987 & 1,36 & 0,47 & 3,83 & 0,74 \\
\hline 1988 & 1,74 & 0,90 & 1,52 & 0,49 \\
\hline 1989 & 1,69 & 0,55 & 2,25 & 0,85 \\
\hline 1990 & 1,55 & 0,86 & 1,37 & 0,43 \\
\hline 1991 & 2,07 & 0,87 & 2,51 & 0,61 \\
\hline 1992 & 3,00 & 0,61 & 1,29 & 0,36 \\
\hline 1993 & 1,73 & 0,47 & 1,47 & 0,40 \\
\hline 1994 & 2,25 & 1,27 & 1,22 & 0,49 \\
\hline 1995 & 1,89 & 0,84 & 1,80 & 0,51 \\
\hline 1996 & 2,12 & 0,54 & 1,69 & 0,48 \\
\hline 1997 & 1,12 & 0,40 & 0,80 & 0,44 \\
\hline 1998 & 1,23 & 1,08 & 0,79 & 0,54 \\
\hline 1999 & 1,00 & 0,37 & 0,72 & 0,49 \\
\hline 2000 & 1,17 & 0,54 & 0,52 & 0,45 \\
\hline 2001 & 0,87 & 0,32 & 0,90 & 0,46 \\
\hline 2002 & 1,60 & 0,70 & 0,66 & 0,43 \\
\hline 2003 & 1,42 & 0,32 & 0,99 & 0,53 \\
\hline 2004 & 0,77 & 0,37 & 0,49 & 0,68 \\
\hline 2005 & 1,11 & 0,41 & 0,48 & 0,65 \\
\hline 2006 & 1,11 & 0,42 & 1,28 & 0,52 \\
\hline
\end{tabular}

Fonte: Cálculos dos autores a partir de dados primários da EMATER-RS.

Tabela 4 - Índices de preços médios anuais pagos ao produtor dos principais produtos hortifrutigranjeiros do Rio Grande do Sul (base 100 em 1986).

\begin{tabular}{|c|c|c|c|c|}
\hline \multicolumn{4}{|c|}{ Produtos de Safra } & Produtos de série contínua \\
\hline Produto & Uva de mesa & Bergamota & Maçã & Aipim \\
\hline \multicolumn{5}{|l|}{ Ano } \\
\hline 1986 & 100,00 & 100,00 & 100,00 & 100,00 \\
\hline 1987 & 49,07 & 40,96 & 204,79 & 78,00 \\
\hline 1988 & 62,65 & 78,45 & 81,47 & 51,73 \\
\hline 1989 & 60,86 & 48,07 & 120,60 & 89,88 \\
\hline 1990 & 55,87 & 75,36 & 73,21 & 45,40 \\
\hline 1991 & 74,86 & 75,82 & 134,03 & 64,21 \\
\hline 1992 & 108,19 & 53,67 & 69,18 & 38,08 \\
\hline 1993 & 62,31 & 41,47 & 78,59 & 41,92 \\
\hline 1994 & 81,17 & 111,19 & 65,22 & 51,17 \\
\hline 1995 & 68,17 & 73,11 & 96,20 & 53,68 \\
\hline 1996 & 76,42 & 47,38 & 90,27 & 50,71 \\
\hline 1997 & 40,31 & 35,05 & 42,91 & 46,38 \\
\hline 1998 & 44,43 & 94,32 & 42,51 & 56,77 \\
\hline 1999 & 36,05 & 32,50 & 38,34 & 51,86 \\
\hline 2000 & 42,26 & 46,80 & 27,94 & 47,74 \\
\hline 2001 & 31,33 & 28,07 & 48,26 & 48,00 \\
\hline 2002 & 57,85 & 61,18 & 35,39 & 44,70 \\
\hline 2003 & 51,20 & 27,79 & 52,73 & 55,43 \\
\hline 2004 & 27,88 & 32,35 & 26,35 & 71,15 \\
\hline 2005 & 40,24 & 35,64 & 25,69 & 68,14 \\
\hline 2006 & 40,24 & 36,76 & 68,57 & 54,88 \\
\hline
\end{tabular}

Fonte: Cálculos dos autores a partir de dados primários da EMATER-RS.

Ciência Rural, v.40, n.7, jul, 2010. 
Tabela 5 - Parâmetros e estatística $t$-student para a regressão nos diferentes períodos.

\begin{tabular}{|c|c|c|c|}
\hline & \multicolumn{3}{|c|}{ Período } \\
\hline Produto & $1973-2006$ & $1973-1994$ & $1995-2006$ \\
\hline “t” tabelado a 95\% de significância & $2,030 *$ & 2,080 & 2,201 \\
\hline \multicolumn{4}{|l|}{ Cebola } \\
\hline Parâmetro “a” & 3,173 & 3,521 & 0,809 \\
\hline Parâmetro “b” & $-0,091$ & $-0,130$ & $-0,005$ \\
\hline “t” calculado & 13,640 & 8,669 & 0,558 \\
\hline \multicolumn{4}{|l|}{ Tomate } \\
\hline Parâmetro “a” & 3,219 & 3,117 & 1,742 \\
\hline Parâmetro “b” & $-0,062$ & $-0,049$ & $-0,055$ \\
\hline “t” calculado & 16,089 & 5,430 & 6,958 \\
\hline \multicolumn{4}{|l|}{ Batata } \\
\hline Parâmetro “a” & 1,980 & 2,068 & 0,634 \\
\hline Parâmetro “b” & $-0,045$ & $-0,053$ & 0,017 \\
\hline “t” calculado & 11,350 & 5,810 & 2,487 \\
\hline \multicolumn{4}{|l|}{ Laranja } \\
\hline Parâmetro “a” & 0,745 & 0,662 & 0,443 \\
\hline Parâmetro "b” & $-0,013$ & $-0,003$ & $-0,018$ \\
\hline “t” calculado & 10,588 & 1,343 & 3,283 \\
\hline \multicolumn{4}{|l|}{ Pêssego** } \\
\hline Parâmetro “a” & 3,064 & 3,077 & 2,063 \\
\hline Parâmetro "b" & $-0,060$ & $-0,064$ & $-0,115$ \\
\hline “t” calculado & 12,244 & 7,860 & 3,472 \\
\hline
\end{tabular}

Fonte: Cálculos dos autores a partir de dados primários da EMATER-RS.

* $t$ tabelado para 35 graus de liberdade, em razão do intervalo da tabela passar diretamente de 30 para 35.

**Valores equivalentes à safra. (Ex.: 1973 = Safra 1973/74).

Tabela 6 - Parâmetros e estatística $t$-student para a regressão nos diferentes períodos.

\begin{tabular}{|c|c|c|c|}
\hline & \multicolumn{3}{|c|}{ Período } \\
\hline Produto & $1986-2006$ & $1986-1994$ & $1995-2006$ \\
\hline “t” tabelado a 95\% de significância & 2,086 & 2,306 & 2,201 \\
\hline \multicolumn{4}{|l|}{ Uva de mesa* } \\
\hline Parâmetro “a” & 2,211 & 1,887 & 1,651 \\
\hline Parâmetro “b” & $-0,062$ & 0,032 & $-0,070$ \\
\hline “t” calculado & 6,341 & 0,775 & 3,742 \\
\hline \multicolumn{4}{|l|}{ Bergamota* } \\
\hline Parâmetro “a” & 0,885 & 0,777 & 0,700 \\
\hline Parâmetro "b" & $-0,024$ & 0,005 & $-0,032$ \\
\hline “t” calculado & 5,212 & 0,216 & 3,299 \\
\hline \multicolumn{4}{|l|}{ Maçã* } \\
\hline Parâmetro “a” & 2,297 & 2,584 & 1,005 \\
\hline Parâmetro “b” & $-0,094$ & $-0,165$ & $-0,016$ \\
\hline “t” calculado & 8,911 & 3,106 & 0,798 \\
\hline \multicolumn{4}{|l|}{ Aipim } \\
\hline Parâmetro “a” & 0,625 & 0,817 & 0,460 \\
\hline Parâmetro “b” & $-0,008$ & $-0,057$ & 0,010 \\
\hline “t” calculado & 2,897 & 5,362 & 3,383 \\
\hline
\end{tabular}

Fonte: Cálculos dos autores a partir de dados primários da EMATER-RS.

* Valores equivalentes à safra. (Ex.: 1973 = Safra 1973/74).

Ciência Rural, v.40, n.7, jul, 2010. 


\section{REFERÊNCIAS}

ABBA. Batata Brasil: área, produção e produtividade. Itapetininga: Associação Brasileira da Batata, 2008. Acesso em: 27 mar. 2008. Online. Disponível em: <http:// www.abbabatatabrasileira.com.br/brasil_area.htm>>.

ABECITRUS. Produção de laranja. São Paulo: Associação Brasileira dos Exportadores de Citrus, 2008. Acesso em: 27 mar. 2008. Online. Disponível em: <http:// www.abecitrus.com.br/producao_br.html>.

ALMEIDA, C.O. de. Fruticultura brasileira em análise. Viçosa. Portal do Agronegócio, 2008. Acesso em: 10 set. 2008. Online. Disponível em: <http://www.portaldoagronegocio.com.br>.

CARDOSO, C.E.L. et al. Fruticultura tropical: perspectiva e tendências. Revista Econômica do Nordeste, Fortaleza, v.31, n.1, p.84-95, 2000. Disponível em: <http://www.bnb.gov.br/>. Acesso em: out. 2007.

FERNANDES, M.S.A. Cadeia produtiva da fruticultura. In: CNPq. Agronegócio brasileiro; ciência, tecnologia e competitividade. Brasília: CNPq, 1998. p.201-214.

FINAMORE, E.B.M.C.; GOMES A.P. Uma alternativa à análise de tendência em séries temporais. In: CONGRESSO BRASILEIRO DE ECONOMIA E SOCIOLOGIA RURAL, 37.,
1999, Foz do Iguaçu, PR. Anais... Brasília: SOBER, 1999. 1 CD.

Johnston, J. Métodos econométricos. São Paulo: Atlas, 1977. 313p.

Kazmier, L.J. Estatística aplicada à economia e administração. São Paulo: McGraw-Hill, 1982. 376p.

SOUZA, R.S. de et al. Tendência histórica de preços pagos ao produtor na pecuária do Rio Grande do Sul, Brasil. Ciência Rural, Santa Maria, v.36, n.5, p.1511-p.1517, 2006. Disponível em: <http://www.scielo.br/scielo.php?pid=S0103$84782006000500026 \&$ script $=$ sci_abstract $\&$ tlng $=p t>$. Acesso em: maio, 2008. doi: 10.1590/S0103-84782006000500026.

SOUZA, R.S. de; VIANA, J.G.A. Tendência histórica de preços pagos ao produtor na agricultura de grãos do Rio Grande do Sul, Brasil. Ciência Rural, Santa Maria, v.37, n.4, p.1128-1133, 2007. Disponível em: <http://www.scielo.br/scielo.php?pid=S010384782007000400034\&script=sci_arttext\&tlng=em $>$. Acesso em: maio, 2008. doi: 10.1590/S0103-84782007000400034.

VILELA, N.J.; HENZ, G.P. Situação atual da participação das hortaliças do agronegócio brasileiro e perspectivas futuras. Cadernos de Ciência \& Tecnologia, Brasília, v.17, n.1, p.7189, 2000. Disponível em: <http://link.periodicos.capes.gov.br>. Acesso em: nov. 2007. 